
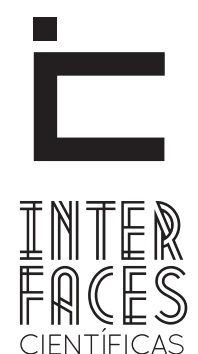

EDUCAÇÃO

ISSN IMPRESSO 2316-333X

E-ISSN 2316-3828

DOI 10.17564/2316-3828.2016v4n2p43-58

\title{
DIVERSIDADE LINGUIISTICA E MULTILINGUISMO EM DOCUMENTOS NORTEADORES DE POLIITICAS PARA O ENSINO DE LÍNGUAS NO BRASIL
}

Cibele Krause-Lemke ${ }^{1}$

\section{RESUMO}

Este trabalho tem como objetivo responder a seguinte pergunta: os textos reguladores desenvolvidos sobre o ensino e aprendizagem de línguas estrangeiras no Brasil contemplam as realidades multilíngues ou a diversidade linguística? Para tentar respondê-la, apresentamos, neste estudo, um panorama a respeito de como os documentos norteadores de políticas para o ensino de línguas no Brasil, publicados entre 2000 a 2008, abordaram esta temática. Esta leitura tem por base os postulados de Bourdieu (2008), o qual trata sobre a produção e reprodução de uma língua legíti- ma. Percebe-se que, embora a discussão sobre a diversidade linguística e multilinguismo apareça nos textos reguladores mais recentes, estes conceitos ainda não estão plenamente incorporados aos grandes debates a respeito do ensino de línguas no Brasil.

\section{PALAVRAS-CHAVE}

Textos Reguladores. Diversidade Linguística. Multilinguismo. Ensino de Línguas. 


\section{ABSTRACT}

This paper aims to answer the following question: do regulatory texts developed on teaching and learning foreign languages in Brazil include the multilingual realities or linguistic diversity? To try to answer it, I present in this study an overview on how the guiding document policies for language teaching in Brazil published between 2000 to 2008, addressed this issue. This reading is based on Bourdieu's postulates (2008), which deals with the production and reproduction of a legitimate language. It can be seen that although the discussion of linguistic diversity and multilingualism to appear in the most recent regulatory texts, these concepts are not fully incorporated into the great debates about language teaching in Brazil.

\section{KEYWORDS}

Official guideline documents. Linguistic diversity. Multilingualism. language teaching.

\section{RESUMEN}

Este estudio tiene como objetivo responder a la siguiente pregunta: ¿textos normativos desarrollados en la enseñanza y aprendizaje de lenguas extranjeras en Brasil incluyen las realidades plurilingües o la diversidad lingüística? Para tratar de responderla, se presentan en este estudio, una visión general de cómo las políticas de documento guía para la enseñanza de idiomas en Brasil, publicados desde 2000 a 2008, abordan este tema. Esta lectura se basa en los postulados de Bourdieu (2008), que se ocupa de la producción y reproducción de una lengua legítima. Se puede observar que a pe- sar de la discusión de la diversidad lingüística y el plurilingüismo aparecer en los más recientes textos normativos, estos conceptos no están plenamente incorporadas en los grandes debates sobre la enseñanza de idiomas en Brasil.

\section{PALABRAS CLAVE}

Textos normativos. Diversidad lingüística. Multilingüismo. La enseñanza de idiomas. 


\section{INTRODUÇÃO}

Este trabalho tem como objetivo responder a seguinte pergunta: os textos reguladores desenvolvidos sobre o ensino e aprendizagem de línguas estrangeiras no Brasil contemplam as realidades multilíngues ou a diversidade linguística? Para tentar respondê-la, apresento, neste estudo, um panorama a respeito de como os documentos norteadores, especificamente os Parâmetros Curriculares Nacionais e as Diretrizes Curriculares (DC) para o ensino de Línguas Estrangeiras Modernas do Paraná, publicados entre 2000 a 2008, abordaram esta temática.

A problemática investigada ampara-se no suposto apagamento das realidades multilíngues do Brasil, dada a generalização com a qual se trata do conceito ‘língua' em território brasileiro. Como é sabido, sempre se trabalhou para inserir no imaginário brasileiro a noção de que o país é monolíngue, resquício ainda das políticas de branqueamento e repressão linguística que imperaram no Brasil durante o governo de Getúlio Vargas (1930 - 1945). No entanto, várias línguas sempre foram faladas em território nacional e, apesar de algumas terem sido extintas, outras permanecem. Esse imaginário provoca dois apagamentos: i) a constituição heterogênea do Brasil e, ii) as vozes dos que são imigrantes.

Assim, dedico-me à leitura e análise dos textos que regulamentam o ensino de línguas no Brasil, tanto em relação às orientações nacionais, quanto às estaduais, tendo como referência o estado do Paraná.

Esta leitura terá por base o estudo do que Bourdieu (2008) a partir de seu livro A economia das trocas lingüísticas, no qual trata sobre a produção e reprodução de uma língua legítima. Assim, para a compreensão de como funcionam os textos reguladores, o debate sobre a língua como poder simbólico parece ter especial relevância.
Para esta análise, baseio-me também na perspectiva de Authier-Revuz (1998) sobre a D.C., pois entendo que os textos reguladores cumprem dois papéis fundamentais: i) retomam e se retroalimentam de saberes produzidos por certos grupos, e portanto, podem funcionar como mais um elemento de D.C. e, ii) ao trazerem aos professores os saberes produzidos na universidade, apresentam um modo de fazer atrelado e que responde, por sua vez, ao seu papel regulamentador.

Considerando esse papel regulamentador das orientações curriculares no que tange ao ensino de línguas, abro esta discussão com o que Bourdieu postula sobre que seria o poder simbólico da língua. Assim como afirma Pêcheux ao dizer que "não há discurso científico puro” (PÊCHEUX, 1995, p. 189), Bourdieu (2008, p. 27) articula a ideia de que "não existem mais palavras inocentes”. O primeiro afirma isso em relação à carga histórica que está imersa em todo e qualquer discurso e, o segundo, leva o leitor a essa reflexão da linguagem em relação ao empoderamento que ela dá aos falantes.

Em virtude de que a língua é um mecanismo formal cujas capacidades de produção são inesgotáveis, o sujeito que domina as formas do dizer - sendo que estas formas do dizer, na concepção de Bourdieu (2008), estão atreladas à forma padrão da língua - pode tudo enunciar. 0 fato de que esse sujeito, ou falante, esteja 'dotado' desta capacidade - o domínio correto das formas linguísticas segundo a língua padrão - concede-lhe garantias de poder absoluto, pela linguagem. Tal fato pode incluir, como diz Bourdieu (2008, p. 28), “a produção de discursos formalmente corretos, mas semanticamente vazios".

Como isso se estabelece as zonas de poder: o que pode constituir um conhecimento legítimo e ilegítimo da língua. Ao trabalhar com estes dois referentes, Bourdieu faz uma crítica aos estudos chomskyanos 
que postulam a existência um falante-ouvinte-ideal, cuja característica principal é a participação em uma sociedade dita homogênea e que conhece perfeitamente a sua língua. Este falante ideal, portanto, teria o conhecimento legítimo da língua. Todos os que fogem a este parâmetro de descrição estariam atrelados ao conhecimento ilegítimo da língua.

Parece-me que o legado da teoria sociológica de Bourdieu (2008) está em alertar para o fato de que nem todos os falantes são considerados como tendo um conhecimento legítimo da língua e, ainda, que a imposição de um conhecimento tido como legítimo serve para frear as vozes daqueles que estão imersos num processo de dominação simbólica, via uso da língua, cujo cerne da dominação encobre uma questão de mercados. Tal fato, como já abordado na parte inicial deste trabalho, pode ser vinculado à noção de estigma, ou seja, o falante não julga o seu conhecimento da língua como legítimo. Ou, ainda, como afirma Bourdieu (2008, p. 30):

[...] ao converter as leis imanentes do discurso legítimo em normas universais da prática linguística adequada, escamoteia a questão das condições econômicas e sociais de aquisição de competência legítima e da constituição do mercado onde se estabelece e se impõe esta definição de legítimo e do ilegítimo.

Essa discussão da língua una e legítima conduz para o exercício de leitura dos textos reguladores do ensino. Inicio com uma discussão sobre políticas linguísticas, bem como com as políticas linguísticas direcionadas à diversidade, e, na sequência, apresento a leitura dos documentos reguladores.

Embora o Brasil seja constituído por diversas etnias, idiomas e culturas, estas marcas que o identificam como País parecem estar apagadas nas políticas educacionais brasileiras. Um dos argumentos que sustenta esta afirmação está ancorado na própria implantação de uma política que atenda a realidade indígena, por exemplo. A história mostra que tais leis foram formuladas há bem pouco tempo (embora a es- colarização dos indígenas esteja marcada por quase cinco séculos de história, algumas propostas educativas baseadas numa educação multicultural datam dos anos de 1994 e 1995).

No Brasil, as leis e os encaminhamentos metodológicos que regulamentam o ensino de línguas nas escolas estão descritas nas Leis de Diretrizes e Bases da Educação (LDB), nos Parâmetros Curriculares Nacionais (PCN's) e nas diretrizes específicas de cada estado brasileiro. 0 ensino de línguas estrangeiras torna-se obrigatório a partir da quinta série do ensino fundamental, conforme a LDB promulgada em dezembro de 1996. O Art. 26, § $5^{\circ}$ dispõe que: "Na parte diversificada do currículo será incluído, obrigatoriamente, a partir da quinta série, o ensino de pelo menos uma língua estrangeira moderna, cuja escolha ficará a cargo da comunidade escolar, dentro das possibilidades da instituição".

Já em relação ao ensino médio, o Art. 36, inciso III estabelece que "será incluída uma língua estrangeira moderna, como disciplina obrigatória, escolhida pela comunidade escolar, e uma segunda, em caráter optativo, dentro das possibilidades da instituição".

As expressões grifadas em itálico merecem atenção ao considerar a seguinte argumentação:

i) No que tange ao lugar das línguas estrangeiras em sala de aula, elas não aparecem no núcleo central, mas, na parte diversificada, o que diminui a sua importância se comparada com o estabelecimento de outras disciplinas do currículo escolar;

ii) Ao indicarem a inserção de uma língua estrangeira moderna, apaga as possibilidades de inserção das línguas das comunidades de imigrantes;

iii) Ao proporem a inclusão de uma segunda língua estrangeira no currículo do ensino médio, em caráter optativo, uma vez mais escamoteia as possibilidades reais de que isso aconteça; 
iv) Em vista de seu caráter optativo, revela-se a inexistência de uma política de estímulo para que outras línguas venham a integrar o currículo das escolas, o que acarreta o não desenvolvimento de políticas diferenciadas para formação de professores.

Há, ainda, outro documento, produzido em 2006 pelo Ministério da Educação e editado por Cynthia Duk, o qual foi elaborado no contexto das escolas do MERCOSUL, mas apenas em um momento trata das realidades linguísticas inerentes aos países do bloco, no capítulo sobre "Educação Intercultural", o qual aborda a realidade indígena Mapuche (DUK, 2006, p. 81-83).

Já para as línguas de imigração, não há um documento que estabeleça o seu ensino em contextos colonizados por imigrantes, a não ser naqueles municípios brasileiros que, nas suas legislações locais, assumem a sua identidade multilíngue.

Segundo Oliveira (2004) há três conceitos-chave quando se trata da definição de políticas linguísticas: Política linguística, Planificação linguística e Politologia lingüística, sendo estas as suas definições:

1. Política lingüística é o conjunto de decisões que um grupo de poder, sobretudo um Estado (mas, também uma Igreja ou outros tipos de instituições de poder menos totalizantes) toma sobre o lugar e a forma das línguas na sociedade, e a implementação destas decisões; 2. Planificação lingüística são propostas para modificar a realidade lingüística - do status de uma língua em relação a outra ou de aspectos de sua forma - e se referem ao futuro da relação entre as línguas. Um processo de planificação lingüística posta em marcha passa a ser uma política lingüística. As políticas lingüísticas podem ser 'in vivo' quando decididas e implementadas em meio as atribulações políticas em geral, ou 'in vitro', quando seu planejamento e execução se dão de forma separada e seqüencial, em geral de forma minuciosa.

3. Politologia lingüística, finalmente, conceito criado por Louis-Jean Calvet (2002) é a ciência ou ótica que estuda as políticas lingüísticas, os processos de planificação lingüística e, portanto, também as políticas historiográficas das línguas. (OLIVEIRA, 2004, p. 38).
No Brasil, as decisões frente à política e à planificação linguística, neste caso, ficam atreladas à soberania do Estado, por meio do que estabelecem as regulamentações elaboradas pelo Ministério da Educação e pelas Secretarias Estaduais de Educação. Tais regulamentações apontam direcionamentos para organização do currículo escolar e para as disciplinas a serem ofertadas, tendo por norte os princípios estabelecidos pela Lei de Diretrizes e Bases da Educação, nos quais se incluem as especificações para o trabalho com a língua estrangeira.

Os PCN's do Ensino Fundamental assinalam dois pontos sobre o ensino de línguas na educação básica:

\begin{abstract}
[...] conhecer características fundamentais do Brasil nas dimensões sociais, materiais e culturais como meio para construir progressivamente a noção de identidade nacional e pessoal e o sentimento de pertinência ao país; e conhecer e valorizar a pluralidade do patrimônio sociocultural brasileiro, bem como aspectos socioculturais de outros povos e nações, posicionando-se contra qualquer discriminação baseada em diferenças culturais, de classe social, de crenças, de sexo, de etnia ou outras características individuais e sociais. (BRASIL, 2000, p. 7).
\end{abstract}

No que diz respeito à valorização das línguas das comunidades locais, expressa o que segue:

A convivência entre comunidades locais e imigrantes ou indígenas pode ser um critério para a inclusão de determinada língua no currículo escolar. Justifica-se pelas relações envolvidas nessa convivência: as relações culturais, afetivas e de parentesco. Por outro lado, em comunidades indígenas e em comunidades de surdos, nas quais a língua materna não é o português, justifica-se o ensino de Língua Portuguesa como segunda língua. (BRASIL, 2000, p. 23).

Embora estejam presentes questões relacionadas à valorização das línguas e da diversidade sociocultural no contexto escolar, há um apelo forte à criação de uma identidade nacional e de pertença ao país. Em vista disso, é possível questionar sobre as imagens de sujeito que podem existir subjacentes à afirmação e, também, sobre as suposições que fa- 
zem os organizadores do documento em relação ao ensino de línguas nas escolas brasileiras.

Tais inquietudes são importantes para pensar a respeito da relação que se estabelece entre as línguas de imigração com a língua oficial. Relação que, $a$ priori, resulta de uma preocupação política, ao figurar como ponto importante ao planejar as línguas a serem ensinadas, mas que se traduz em outra política, a qual serve para estabelecer o papel hegemônico de uma só língua. Ao mesmo tempo em que está de acordo em considerar a diversidade linguística brasileira, podendo incluir no currículo escolar o ensino de línguas que tenham sua validade no contexto social, orienta este ensino tendo por base o desenvolvimento de princípios de uma identificação nacional.

Assim, a esta política de valorização subjaz um ideal de apagamento da diversidade. Sobre esta afirmação cabe dizer que não são necessárias práticas de valorização das línguas sejam elas oficiais, minoritárias, estrangeiras. São necessárias, sim, políticas que as incorporem aos repertórios linguísticos dos aprendizes e que sejam reconhecidas como legítimas em seus contextos (BARZOTTO, 2008).

No que se segue a análise dos textos reguladores se dará a partir de três publicações do Ministério da educação: os PCN's (2000), PCN's + (2002), as OC's (2006), e as DCE's (2008). Cabe ressaltar que a análise dos documentos se centralizará naqueles que regulam a etapa do Ensino Médio.

\section{OS PARÂMETROS CURRICULARES NACIONAIS [2000]-PCN'S}

As orientações para o ensino de Língua Portuguesa e de Língua Estrangeira fazem parte de um documento maior - elas estão descritas no caderno de "Linguagens, Códigos e suas Tecnologias”, nos quais também se encontram as orientações para outras disciplinas do currículo escolar: Artes, Educação Física e Infor- mática. Há uma base legal que perpassa o documento na qual são explicitadas e descritas a Lei de Diretrizes e Bases da Educação, bem como as concepções para o trabalho pedagógico no Ensino Médio (EM).

A abordagem dos PCN's é permeada por três objetivos principais: o primeiro deles é o objetivo instrumental, cuja finalidade é levar o aprendiz ao desenvolvimento de práticas linguísticas na língua materna ${ }^{1} \mathrm{e}$ estrangeira; o segundo objetivo é o educativo, em que se objetiva a formação integral do aprendiz, sobretudo no que concerne à reflexão ética, à reflexão sobre conceitos de análise e de observação e, por último, o objetivo cultural, sendo que este elemento da formação dará condições ao aluno para atuar comunicativamente em outras realidades linguísticas.

O exame das concepções norteadoras do documento foi efetuado a partir do texto que trata do ensino de Língua Portuguesa, momento em que estabelecem as bases para o trabalho com a linguagem. Neste caso, não são abordados os princípios psicológicos das abordagens sobre aquisição de línguas. São tratados, apenas, os conceitos epistemológicos de base. $\mathrm{Na}$ parte que concerne às línguas estrangeiras, tais conceitos não são retomados nem rediscutidos.

A perspectiva teórica que norteia a abordagem dos PCN's é a de linguagem, primeiro, como capacidade humana e, logo, como interação social, aos moldes do que propõe a teoria vygotskyana. Pode-se observar, portanto, este cruzamento de concepções que orientam o documento. Uma que remete ao inatismo, quando afirma que "a linguagem é capacidade humana de articular significados” (BRASIL, 2000, p. 5) e, outra, que se espraia para os conceitos defendidos por Bakhtin, já que as práticas sociais transformam-se em arena de conflitos ou, como sinaliza do documento, em "relações de força entre os interlocutores” (BRASIL, 2000, p. 6).

\footnotetext{
1. Neste caso, mantém o termo designado nos PCN's para a Língua Portuguesa. No documento consta ora língua materna, ora língua portuguesa. Neste caso, observar as considerações já efetuadas sobre as implicações de usar
} um ou outro termo indistintamente. 
No tocante à concepção de sujeito, esta se mostra atrelada, também, à concepção sócio-histórica, já que, segundo postula o documento, o sujeito é sempre visto em relação ao outro, em interação: "O homem [é] visto como um texto, que constrói textos" (PCN's, 2000, p. 18). As noções de língua e de sujeito vão se entrelaçando, tentando formar um 'todo' coerente. A identidade, pois, é construída na e pela língua materna - sempre definida como sendo a Língua Portuguesa -, a qual é concebida como a depositária da memória do sujeito.

É nesta explanação que se pontua o conhecimento e compreensão do Português como língua "geradora de significação e integradora da organização de mundo e da própria identidade do falante" (BRASIL, 2000, p. 10). Esta afirmação é elucidativa, pois manifesta, na materialidade da linguagem, o status da língua portuguesa frente às outras línguas que se falam no Brasil - ocupando, assim, o espaço de única língua que se fala em território brasileiro.

As definições apresentadas no documento recuperam, em parte, os atuais debates no campo da Linguística Aplicada e da Educação e com isso pretendem instaurar e orientar práticas que correspondam às reflexões atuais. No entanto, isso não quer dizer que, de fato, elas sejam incorporadas ao fazer pedagógico. Neste sentido, há que se destacar as condições de produção de documentos desta natureza, já que quem os escreve não os faz por uma demanda particular, mas a ele é incumbida a tarefa de produzi-los.

Um dos temas que se sobressai, tanto no PCN's do Ensino Fundamental quanto do Ensino Médio, está relacionado à valorização das variedades, conforme constam nas páginas sete e nove do documento e encontram-se transcritas nos excertos a seguir:

[Excerto1]: no estudo da linguagem verbal, a abordagem da norma padrão deve considerar sua representatividade, como variante lingüística de determinado grupo social, e o valor atribuído a ela, no contexto de legitimações sociais. Aprende-se a valorizar determina- da manifestação, porque socialmente ela representa o poder econômico e simbólico de certos grupos sociais que autorizam sua legitimidade. (BRASIL, 2000, p. 7).

[Excerto 2]: respeitar e preservar as diferentes manifestações da linguagem utilizadas por diferentes grupos sociais, em suas esferas de socialização; usufruir do patrimônio nacional e internacional, com suas diferentes visões de mundo e construir categorias de diferenciação, apreciação e criação. (BRASIL, 2000, p. 9).

Assim, pois, percebe-se que o foco de trabalho está no "respeito", na "valorização", na "consideração" de variedades linguísticas, sem que de fato haja uma proposta de reflexão sobre estes discursos que, em última instância, constitui o capital social de cada falante. Tal posição é explicitada, sobretudo, nas linhas finais do excerto [2], por meio de um processo de inculcação de uma determinada variedade como certa. Ao criticar a noção de estilo, Bourdieu (2008, p. 25) afirma:

[...] esse 'desvio individual em relação à norma lingüística', essa elaboração especial que tende a conferir ao discurso propriedades distintivas, é um ser-percebido que existe apenas em relação com sujeitos perceptores, dotados dessas disposições diacríticas, que permitem estabelecer distinções entre maneiras de dizer diferentes, artes de falar distintivas.

Em outras palavras, o exercício de julgamento daquilo que é mais apropriado, ou não, segundo as situações comunicativas, sempre parte deste "um" que tem o poder de autorizar ou desautorizar as práticas linguísticas (BARZOTTO, 2008).

No que concerne às línguas estrangeiras, a centralidade dos objetivos desta etapa está em ensiná-las para o mundo do trabalho. 0 domínio de uma língua estrangeira está atrelado ao desenvolvimento de melhor posição profissional.

Como abordado no início desta análise, quando tratam das línguas estrangeiras, os conceitos de língua e de sujeito não são retomados. As alterações mais evidentes referem-se às concepções teóricas que 
norteiam o seu ensino, bem como o desenvolvimento de competências e de habilidades relacionadas à:

- Saber distinguir entre variantes linguísticas;

- Escolher os registros mais adequados à comunicação;

- Escolher o vocábulo que melhor reflita a ideia que pretende comunicar;

- Compreender de que forma determinada expressão pode ser interpretada em razão de aspectos sócias e/ou culturais

- Compreender em que medida os enunciados refletem a forma de ser, pensar, agir e sentir de quem os produz;

- Utilizar os mecanismos de coerência e coesão na produção em língua estrangeira (oral e/ou escrita). Todos os textos referentes à produção e à recepção em qualquer idioma regem-se por princípios gerais de coerência e de coesão e, por isso, somos capazes de entender e de sermos entendidos.

- Utilizar as estratégias verbais e não verbais para compensar falhas na comunicação (como o fato de não ser capaz de recordar, momentâneamente, uma forma gramatical, lexical) para favorecer a efetiva comunicação e alcançar o efeito pretendido (falar mais lentamente ou enfatizando certas palavras de maneira proposital para obter determinados efeitos retóricos, por exemplo). (BRASIL, 2000, p. 28-29).

Nesse sentido, a sustentação teórica do documento é dirigida pela opção da competência linguístico-comunicativa, cabendo à escola resgatar o papel formador no que diz respeito à aprendizagem de línguas. Segundo o documento, tal papel vem sendo desempenhado pelos cursos livres de idiomas. Salienta-se, ainda, o desenvolvimento da competência comunicativa, o que, nesta instância, remete ao movimento que há em relação aos saberes acerca da abordagem comunicativa produzidos no âmbito da academia. Constata-se, portanto, uma relação direta entre ambos os discursos:

[Excerto 3]: Embora seja certo que os objetivos práticos - entender, falar, ler e escrever - a que a legislação e especialistas fazem referência são importantes, quer nos parecer que o caráter informativo intrínseco à aprendizagem de línguas de línguas estrangeiras não pode ser ignorado. Torna-se pois, fundamental, conferir ao ensino escolar de Línguas Estrangeiras um caráter que, além de capacitar o aluno a compreender e a pronunciar enunciados corretos na novo idioma propicie ao aprendiz a possibilidade de atingir um nível de competência lingüística capaz de permitir-lhe acesso a informações de vários tipos ao mesmo tempo em que contribua para a sua formação geral enquanto cidadão. (BRASIL, 2000, p. 26).

No ensino médio, há a possibilidade de inclusão de mais de uma língua estrangeira no currículo escolar, sendo que a decisão de quais línguas ensinar é colocada a cargo de cada estado, de acordo com a representatividade das línguas na região. É citado o caso do Rio Grande do Sul, que em certas regiões podem considerar mais produtiva a inclusão do Italiano no seu currículo escolar. Contudo, na maioria das vezes, acaba escolhendo o inglês, pela sua validade no contexto internacional. Então, como proceder com estas decisões sem um debate político que, de fato, propicie as mudanças necessárias? Quem seriam os professores a assumir a disciplina, sem a criação de cursos nesta área específica?

Como tratado anteriormente acerca das formas de sua incorporação aos contextos, é importante ressaltar que as línguas a serem ofertadas no currículo escolar, previamente escolhidas pela comunidade escolar, são definidas tendo por base a disponibilidade de professores. Neste caso, a exemplo do estado do Paraná, as línguas de imigração só são ofertadas em período contra-turno e obedecem a um número mínimo de alunos inscritos. Do mesmo modo, tal realidade é condicionada, ainda, pela falta de formação de professores nas línguas de imigração, dada a inexistência, até este momento, de cursos de Letras nas áreas específicas dessas línguas.

\section{OS PARÂMETROS CURRICULARES + [2002] - PCN'S +}

Dando continuidade à análise, nos PCN's + há uma revisão e ampliação de conceitos abordados na edição 
antes debatida, publicada no ano 2000. Essa revisão se dá no que concerne à ampliação do debate teórico entre a articulação dos saberes de cada disciplina e a sua forma de ensino, tendo como base um princípio interdisciplinar como norteador.

Ainda que pautem o desenvolvimento do trabalho com a linguagem no binômio competência - habilidades, a nova configuração postula o desenvolvimento de conceitos, tais como os citados a seguir: 1 . Análise e síntese; 2. Correlação; 3. Identidade; 4. Integração; 5. Classificação; 6 . Informação versus redundância; 7 . Hipertexto; 8. Metalinguagem.

A análise a seguir mantém o seu foco nas disciplinas de Língua Portuguesa e de Línguas Estrangeiras Modernas, já que é na primeira que se estabelecem os conceitos-chave que interessam a este trabalho.

Em termos de noção de língua, permanece articulada à corrente sócio-histórica. Porém, ampliam-se as bases de sua discussão e descrição. Entram em jogo as noções de interlocução, significação, dialogismo. Por isso, depreende-se, assim como na primeira versão do documento, que ele transita entre a corrente sócio-histórica e a corrente dialógica, representadas por Vygotsky e Bakhtin, respectivamente, fazendo jogo, também, com as discussões epistemológicas relativas aos dois teóricos citados. O foco na língua materna, neste caso a língua portuguesa, continua bastante explícito:

\footnotetext{
[Excerto 4]: [...] é preciso cultivar a idéia - tanto em professores quanto em alunos - de que a língua materna é um dos principais operadores da comunicação, nas diversas trocas sociais de que participamos cotidianamente. Seus usuários devem saber dispor dela adequadamente nas diversas situações comunicativas, cabendo à escola um importante papel de mediação na aquisição dessa competência. Pela língua, somos capazes de agir e fazer reagir: quando nos apropriamos dela - instaurando um "eu" que dialoga com um "outro" - buscamos atingir certas intencionalidades, determinadas em grande medida pelo lugar de que falamos, e construir sentidos que se completam na própria situação de interlocução. (BRASIL, 2002, p. 74) [Grifos nossos]
}

\begin{abstract}
[Excerto 5]: Desde a infância, todos os falantes de uma língua comunicam-se com base em uma gramática internalizada, que independe de aprendizagem sistemática, pois se adquire pelo contato com os demais falantes. É a partir desse saber lingüístico implícito que os usuários se fazem entender, de uma forma ou de outra, e deixam transparecer as marcas de sua origem, idade, nível sociocultural. (BRASIL, 2002, p. 57. Grifos nossos).
\end{abstract}

Como no Brasil não há leis linguísticas exaradas pelo poder Federal em relação à coexistência de mais língua em nosso território, presume-se que a língua materna a que se referem seja o português.

No que se refere ao sujeito - o falante - a discussão apresenta-se permeada de conceitos sobre linguagem, texto e interação. 0 sujeito é, pois, o aluno, que se vê na iminência de atuar nas práticas situadas de leitura e de escrita. A ele the cabe desenvolver um senso crítico, capaz de depreender pelos textos (verbais ou não verbais) intenções, interpretar os gestos culturais implícitos ou explícitos que emergem das práticas linguísticas, ao mesmo tempo em que lhe permitem atuar com certa autonomia nas práticas linguísticas. Importante ressaltar que essa autonomia não passa de uma ilusão, considerando-se os processos de assujeitamento, via história e via linguagem (CORACINI, 2003). Observe-se o excerto a seguir:

\begin{abstract}
[Excerto 6]: 0 aluno detentor desses conceitos, capaz de identificá-los e de aplicá-los em atos efetivos de comunicação, certamente estará aparelhado para apreender os subentendidos, as entrelinhas e as intenções não-explícitas do falante que com ele entra em situação dialógica. Mais que isso, saberá identificar e utilizar o novo (a rigor, a informação), o elemento surpresa, e opinar sobre sua eficácia em situações determinadas. (BRASIL, 2002, p. 48).
\end{abstract}

Neste caso, assim como estivemos pontuando, há nova recorrência à inserção dos discursos produzidos na academia e que remetem a uma nova abordagem de ensino, ao garantir a centralidade do aluno, mas, sempre realizada a partir de uma noção do que seja a língua e as práticas linguísticas anteriormente estipuladas. 0 foco, 
portanto, está mais centrado na defesa de uma perspectiva do que na consideração da cultura do aluno.

A centralidade dos estudos da linguagem reside na unidade de texto e nas relações dialógicas entre os vários textos que circulam na cultura. Sendo que assim há a clara noção de que cada texto dialoga com outros. Por isso, o conceito também se relaciona com o de intertextualidade, indispensável para a compreensão do diálogo que alimenta a dinâmica da cultura em todos os campos do saber - especialmente no que diz respeito às noções de tradição e ruptura. 0 excerto a seguir oferece um panorama de como isso pode acontecer:

[Excerto 7]: Ocorre, porém, que essa estruturação gramatical básica parece não ser suficiente para garantir o acesso ao universo da cultura e a todas as possibilidades que ele oferece (o direito à informação, à formação de opinião sustentada, à liberdade de escolha, entre outros). Sabe-se que grandes contingentes de excluídos sociais encontram-se apartados do mundo do trabalho e do lazer, ou neles sublocados, porque tiveram pouca ou nenhuma chance de se beneficiar da educação escolar e dos saberes que se podem desenvolver por meio dela. Cabe à escola aprimorar a competência gramatical dos alunos, de modo a levá-los a gerar seqüências próprias, consideradas como admissíveis e aceitáveis no interior da Língua Portuguesa, bem como compreender enunciados distintos. (BRASIL, 2002, p. 57).

Pela análise do excerto anterior, encontra-se uma relação direta com o postulado por Bourdieu (2008), sendo que cabe a escola 'treinar' os usos corretos da língua legítima, "no processo que conduz à elaboração, legitimação e imposição de uma língua oficial, o sistema escolar cumpre função determinante de fabricar semelhanças das quais resulta a comunidade de consciência que é o cimento da nação" (BOURDIEU, 2008, p. 35).

Retomando a discussão sobre o documento em pauta, no que concerne ao aprendizado da língua estrangeira, a aplicação dos conhecimentos está relacionada à possibilidade de ampliar a interação com os outros. No entanto, este aprendizado deverá ser feito por uma prática situada de linguagem, considerando as trocas culturais como importantes neste processo. Através disto, entram em jogo as interpretações de manifestações culturais, já que elas se apresentam por traços singulares.

Um item a ser destacado é o de que, embora enunciem o trabalho com a língua estrangeira por meio dos traços singulares das culturas, na contextualização da disciplina, os exemplos, as argumentações sobre o ensino da língua levam em consideração, sobretudo, a língua inglesa. Deste modo, observa-se a prevalência de duas hegemonias: o português - como língua materna - e o inglês - como língua estrangeira, tal como pode ser observado a seguir:

[Excerto 8]: Sendo a língua um bem cultural e patrimônio coletivo, no estudo de idioma estrangeiro é fundamental a abordagem de aspectos que envolvem a influência de uma cultura sobre a outra. No caso do Inglês, por exemplo, pode-se analisar a influência da cultura norte-americana e da própria língua inglesa sobre outras culturas e idiomas. A ampliação de horizontes culturais passa pela ampliação do universo lingüístico. É indispensável, também, que as aulas de língua estrangeira moderna possibilitem o estudo de grupos culturais (migrantes, rappers, por exemplo) a partir de seus usos linguísticos. (BRASIL, 2002, p. 100).

O ensino das línguas estrangeiras extrapola os limites da comunicação em si mesma e sugere que a reflexão sobre a alteridade transcenda o domínio das habilidades linguísticas. O sujeito aprendiz, neste caso, deve reconhecer-se que, como aprendiz de uma língua estrangeira: ele está no caminho entre usuário e interlocutor de linguagens que estruturam uma identidade cultural própria. Assim,

[Excerto 9]: 0 aprendizado de idiomas estrangeiros deve propiciar que o aluno perceba as possibilidades de ampliação de suas interações com outros. Esse aprendizado, contudo, não deve constituir processo de desvinculação cultural; pelo contrário, é reforçador de trocas culturais enriquecedoras e necessárias para a construção da própria identidade. (BRASIL, 2002, p. 100). 
Um elemento preponderante na abordagem do ensino da língua estrangeira é a vinculação do seu ensino à língua materna que, neste caso, supõe-se que seja a língua portuguesa, já que no Brasil não há acordos políticos para uma educação bilíngue naqueles contextos onde seria válido tê-lo. A língua portuguesa deve estar presente como suporte e como referência e, o aluno, apoiando-se no conhecimento gramatical da primeira língua, estaria mais “apto” para aprender a segunda. Nesse sentido, faz-se importante refletir sobre a utilização desses conceitos naqueles contextos onde coexistem mais de uma língua materna.

A descrição do trabalho com a língua estrangeira vai sendo perpassada por outros conceitos, atrelados àqueles descritos no início desta parte, tal como a reflexão sobre o que é global e/ou local - no sentido de que percebam as influências de usos linguísticos que são apoiados tanto no português quanto em outras línguas estrangeiras - notadamente o inglês. Ainda assim, a compreensão de determinados usos e modismos linguísticos pode ser efetuada a partir do estudo da língua estrangeira, tal como a análise sobre empréstimos e variações dialetais.

\section{AS ORIENTACÕ̃SS CURRICULARES [2006] - OC'S}

Até este momento, estive trabalhando na busca de encontrar como um movimento em direção às realidades linguísticas brasileiras estava sendo incorporado aos documentos reguladores do ensino. Observei que até a publicação do ano de 2002 tal discurso não havia formado parte das discussões veiculadas nesses documentos. A primazia do enfoque estava relacionada nas noções de língua e sujeito. Também, pude perceber que os princípios norteadores do ensino de línguas estrangeiras estavam atrelados aos mesmos princípios da língua materna, com alguns matizes direcionados à consideração de 'outras' culturas, diferenciando-se, então, dos princípios que norteariam o ensino de língua portuguesa no Brasil.
Em relação à terceira publicação, as Orientações Curriculares (2006), esta já se apresenta como uma publicação específica para cada disciplina. Então, se no documento anterior o que norteava o ensino de língua estrangeira eram os mesmos preceitos para o ensino de língua materna, utilizando-me aqui da mesma nomenclatura trabalhada nos PCN's, nesta publicação há uma divisão, inclusive entre as línguas estrangeiras que mais prevalecem no currículo brasileiro: o inglês e o espanhol.

No caso específico da língua espanhola, o documento postula que não se justifica ensiná-la por causa do MERCOSUL, como ainda apregoam alguns textos acadêmicos no exercício de análise realizado, nem por causa do mercado de trabalho. Em outras palavras, constitui-se mais em um gesto político do que pedagógico.

Este documento (Orientações Curriculares - OC's) permanece com os princípios norteadores das versões anteriores, ao manter o debate sobre as concepções de língua e de sujeito situadas na corrente sócio-histórica. Como nas produções anteriores, sinalizam como importante a língua e a cultura materna na aprendizagem da língua e da cultura estrangeira, porém, essa discussão, neste documento, está atrelada à relação de proximidade entre o português e o espanhol. 0 debate profícuo acerca das proximidades e distâncias entre as línguas, nesta versão, parece ganhar outra conotação: de uma aceitação tácita dos princípios da análise linguística, para uma abordagem mais discursiva do fenômeno.

\footnotetext{
[Excerto 10]: A proximidade levou, ao longo dos anos, ao surgimento de estereótipos e de visões simplistas e distorcidas sobre o Espanhol entre nós, as quais, entre outras coisas, reduzem as diferenças a uma lista de palavras consideradas "falsas amigas", induzindo, assim, a uma concepção equivocada de que bastaria conhecer bem todas essas armadilhas para dominar esse idioma. O impulso por contrastar e buscar pontos de aproximação e distância entre essas duas línguas tão "singularmente estrangeiras" (CELADA, 2002) nunca se perdeu, e talvez por isso mesmo, ou quem sabe por
} 
uma certa inércia, persiste a idéia dos "falsos amigos" como os grandes vilões da aprendizagem do Espanhol por brasileiros. (BRASIL, 2006, p. 139).

Sendo assim, retomam a importância do papel da língua materna, em relação à língua estrangeira, no sentido de esta mobilizar as formações identitárias. É neste sentido que surge o termo “identidade" como responsável pelo sucesso ou pelo fracasso na tarefa de aprender línguas, discussão elaborada por Authier-Revuz (1998), ao discorrer sobre a aprendizagem de língua estrangeira, momento em que o "próprio" e o “alheio" entram em conflito.

No excerto que segue, há indícios de uma mobilização em relação à realidade multilíngue brasileira, por meio do uso de um modalizador como devem contemplar, seguido de termos como identidade, plurilinguismo, multiculturalismo, realidade local, tal como explicitado:

[Excerto 11]: Os objetivos a serem estabelecidos para o ensino de Língua Espanhola no nível médio devem contemplar a reflexão - consistente e profunda - em todos os âmbitos, em especial sobre o "estrangeiro" e suas (inter)relações com o "nacional”, de forma a tornar (mais) conscientes as noções de cidadania, de identidade, de plurilingüismo e de multiculturalismo, conceitos esses relacionados tanto à língua materna quanto à língua estrangeira. Para tanto, é necessário levar em conta não só a língua estrangeira, mas, também, a realidade local/regional onde se dá o seu ensino. (BRASIL, 2006, p. 149).

Em relação à abordagem dos conteúdos de língua espanhola, apresentam certa flexibilidade em torno do que deve reger o ensino. Não existem conteúdos pré-estabelecidos, mas apontam para a relação entre temas e contextos como sendo os eixos que podem auxiliar na sua organização. Essas duas categorias teriam uma dupla forma de abordagem: nos contextos onde é possível usar o idioma estrangeiro (a língua espanhola) pode-se abordá-lo partir do contexto. Em outras regiões, supondo-se aquela em que a língua apresenta-se desfocada do contexto social, o ponto de partida seriam os temas.
A proposta sobre o ensino de língua espanhola, ainda, apresenta uma série de reflexões que, notadamente, reúnem os estudos atuais da Linguística Aplicada e da Educação a respeito dos 'deslocamentos' que ocorrem entre língua materna e língua estrangeira. Neste sentido, as autoras do documento postulam que a aprendizagem deveria afastar-se do desenvolvimento de simples comunicações operatórias na língua estrangeira e propiciar o desenvolvimento de comunicações criativas, nas quais o inusitado prevaleça sobre o pré-construído (BRASIL, 2006, p. 132).

Este texto, diferentemente dos demais, recupera a Carta de Pelotas (2000), elaborada no final do II Encontro Nacional sobre Política de Ensino de Línguas Estrangeiras. Esta carta apresenta uma série de discussões sobre o tratamento das línguas estrangeiras na escola: os objetivos reais do ensino de línguas, com vistas à formação integral do aluno, a inserção de uma política linguística que privilegie o ensino bilíngue naqueles contextos onde é cabível, entre outras medidas; o ensino de línguas não somente atrelado ao Inglês e ao Espanhol e, com isso, a proposição de um ensino plurilíngue.

Finalizando esta parte, observamos que houve um largo percurso até que noções da diversidade linguística fossem postas em discussão. Ainda que elas surjam apenas como indicações do que deve ser considerado, é o primeiro momento, em seis anos de produção sobre o ensino e aprendizagem de línguas, que de alguma forma o discurso sobre a pluralidade linguística aparece nesses documentos o que, de certa forma, corrobora a ideia de que há um movimento em relação à necessidade de mudança nas concepções metodológicas de ensino de língua estrangeira.

\section{AS DIRETRIZES CURRICULARES DO ESTADO DO PARANÁ [2008] - DCE'S}

As Diretrizes curriculares do Estado do Paraná constituem-se em um documento elaborado por professores e técnicos das línguas estrangeiras da Se- 
cretaria de Estado da Educação do Paraná (SEED). Sua idealização e construção deram-se a partir de diversos simpósios, reuniões técnicas e programas de formação continuada para que se concretizasse o que hoje norteia a elaboração dos curricula de Língua Estrangeira Moderna (LEM), nos vários Núcleos Regionais de Educação daquele Estado. Ele é, portanto, o documento que descreve e orienta o ensino de línguas na rede estadual de ensino naquele Estado.

Na primeira parte, o documento discorre sobre a dimensão histórica da disciplina de Língua estrangeira no currículo brasileiro. Para tanto, buscam elementos da História, desde a colonização do Brasil, até chegar ao modelo educacional que hoje conhecemos, para explicar o fato do prestígio e desprestígio que as línguas tiveram e ainda têm no plano da educação. Retomam, para tanto, o papel dos jesuítas na catequização dos índios, evangelizando-os e ensinando-os o latim como exemplo de língua culta, submetendo-os, portanto, a um processo de aculturação.

O documento segue com uma reflexão a respeito de como as línguas estrangeiras eram ensinadas, descrevendo as metodologias e os recortes históricos que justificavam determinadas posturas teóricas.

Em relação às concepções de língua, estas são orientadas pela vertente bakhtiniana de linguagem, quando afirmam que a língua se apresenta como espaço de construção discursiva; como prática situada, sendo indissociável, portanto, dos contextos nos quais ela se produz. Além disso, “a língua deixa de lado suas supostas neutralidade e transparência para adquirir uma carga ideológica intensa, e passa a ser vista como um fenômeno carregado de significados culturais" (PARANÁ, 2008, p. 21).

A concepção de sujeito está vinculada à de transformação social pelo conhecimento da linguagem. Ou seja, ao aprender uma língua estrangeira o aluno-sujeito é capaz de negociar outras identidades a partir do confronto com outras culturas, com outras maneiras de ver e de entender as realidades.
As orientações epistemológicas seguem, portanto, as vertentes do discurso, ou seja, todo o ato de linguagem está vinculado à história, sendo que a língua estrangeira, como objeto de aprendizagem, não passa incólume à relação entre cultura, sujeito e identidade.

Por meio do documento, assume-se que hoje em dia há pouco debate sobre os critérios que levam determinadas línguas a ocuparem posições hegemônicas, sendo o espaço do ensino de línguas estrangeiras um lugar legítimo para essas discussões. É neste ínterim que nomeiam as outras realidades étnicas do estado, também a partir do uso do modalizador podem ser e retomam o objetivo de valorização das línguas e histórias dessas comunidades, cuja discussão foi esboçada por mim na abertura deste capítulo. Tais discussões são apresentadas no excerto que segue:

[Excerto 12]: tendo como referência tais reflexões,
depreende-se que tanto a opção teórico-metodológi-
ca quanto o idioma a ser ensinado na escola não são
neutros, mas profundamente marcados por questões
político-econômicas e ideológicas, que resultam mui-
tas vezes do imperialismo de uma língua. Tais ques-
tões marginalizam razões históricas e/ou étnicas que
podem ser valorizadas, levando-se em conta a histó-
ria da comunidade atendida pela escola. (PARANÁ,
2008, p. 17-18).

Percebo, a partir desta leitura, que, antes de um debate pedagógico, há um debate bastante político-ideológico em torno do ensino de línguas na escola. Ou seja, trabalha-se na perspectiva mais de desconstruir o status hegemônico que certas línguas ocupam do que oferecer um lugar legítimo para as línguas de imigração na escola.

Observo, também, que no estado do Paraná esta articulação tem sido efetuada mais diretamente no âmbito metodológico, ao buscar a sustentação da ação docente pautada em discursos sobre a minimização das relações de poder, estabelecidas pelas línguas, usando-se, sobretudo, os saberes produzidos na academia para subsidiar as suas discussões: 
[Excerto 13]: lingüistas aplicados têm estudado e pesquisado novos referenciais teóricos que atendam às demandas da sociedade brasileira e contribuam para uma consciência crítica da aprendizagem e, mais especificamente, da língua estrangeira. Muitos desses trabalhos analisam a função da língua estrangeira com vistas a um ensino que contribua para reduzir desigualdades sociais e desvelar as relações de poder que as apóiam. Tais estudos e pesquisas têm orientado as propostas mais recentes para o ensino de Língua Estrangeira no contexto educacional brasileiro e servem de subsídios na elaboração destas Diretrizes. (PARANÁ, 2008, p. 15).

\section{CONSIDERAÇÕES FINAIS}

De acordo com a proposta deste texto, realizamos um exercício de leitura de documentos reguladores que recobrem oito anos de história em relação ao ensino de línguas nas escolas. Neste exame, pude perceber que os textos reguladores são amparados por discursos convergentes que representam o 'caminhar' dos saberes produzidos na universidade no que tange à explicação dos fenômenos linguísticos, ou seja, os documentos produzidos são amparados, primordialmente, pela produção acadêmica da área dos estudos linguísticos e da educação.

Os saberes veiculados pelos textos reguladores englobam propostas tidas como inovadoras em relação à concepção de língua, sujeitos bem como às concepções metodológicas. Perpassam as abordagens do texto e, após, migram para os gêneros discursivos. $\mathrm{Na}$ língua estrangeira, observa-se a mobilização semethante de teorias, e, por fim, mencionam a emergência das realidades multilíngues.

Ainda, assim, pelo exame efetuado, observo um peso no sentido de afirmar o português como a língua materna de todos os brasileiros. Essa noção perpassa, além da constituição da disciplina - a língua portuguesa como língua materna, também a noção de sujeito e de identidade das disciplinas de língua portuguesa e de língua estrangeira.
As orientações mais recentes retomam o debate do multilinguismo, balançando um pouco os conceitos tão veementemente propagados a respeito de língua e língua materna como sendo conceitos homônimos. Desse fato, pode-se concluir que eles não chegam a provocar alterações no cenário monolíngue estabelecido pelos documentos.

Percebe-se que, embora a discussão sobre a diversidade linguística e multilinguismo apareça nos textos reguladores mais recentes, estes conceitos ainda não estão plenamente incorporados aos grandes debates a respeito do ensino de línguas. É em vista disso que se pode afirmar que há um silenciamento a respeito das realidades linguísticas brasileiras, tal como argumenta Bourdieu (2008) ao afirmar que o próprio estado formula condições para a instauração de uma língua única, da qual surge, também, as relações de poder, via linguagem.

É por isso que a noção de multilinguismo em contexto brasileiro é permeada politicamente pela tensão histórica entre um imaginário de unidade, tensão que não se sustenta em comunidades em que coexistem mais de uma língua.

\section{REFERÊNCIAS}

AUTHIER-REVUZ, Jacqueline. Palavras incertas. As não coincidências do dizer. Campinas: Unicamp, 1998.

BARZOTTO, Valdir Heitor. Variedades linguísticas e formação de professores de língua materna no Brasil.

Conferência: Universitat Autònoma de Barcelona. Barcelona, 2008.

BOURDIEU, Pierre. A economia das trocas

linguísticas: o que falar quer dizer. 2.ed. São Paulo: EDUSP, 2008.

BRASIL. Secretaria de Educação Fundamental.

Parâmetros Curriculares Nacionais: terceiro e quarto 
ciclos do ensino fundamental - Língua Estrangeira ( $5^{\mathrm{a}}$ a $8^{a}$ séries). Brasília: MEC/SEF. Vol 1, 1998.

\section{BRASIL. Parâmetros curriculares nacionais:}

linguagens, códigos e suas tecnologias. Ensino Médio. Língua Estrangeira. Brasília: MEC/SEB. Vol 1, 2000.

\section{BRASIL. Parâmetros curriculares nacionais +:}

linguagens, códigos e suas tecnologias. Ensino Médio. Língua Estrangeira. Brasília: MEC/SEB. Vol 1, 2002.

\section{BRASIL. Orientações curriculares para o ensino} médio: linguagens, códigos e suas tecnologias. Língua Espanhola. Língua Estrangeira. Brasília: MEC/SEF. Vol 1, 2006.

CORACINI, Maria José. Identidade e discurso. (Des) construindo subjetividades. Campinas: Unicamp; Chapecó: Universitária, 2003.
DUK, CYNTHIA. Educar na diversidade: material de formação docente. 3.ed. Edição do material Cynthia Duk. Brasília : [MEC, SEESP], 2006.

OLIVEIRA, Gilvan Müller de. Política Lingüística, Política Historiográfica - Epistemologia e escrita da História da(s) Língua(s) a propósito da língua portuguesa no Brasil Meridional. 2004. Tese (Doutorado) - IEL, UNICAMP, São Paulo, 2004.

PARANÁ. Diretrizes curriculares de língua estrangeira moderna para os anos finais do Ensino Fundamental e para o Ensino Médio. SEED. Curitiba, 2008.

PÊCHEUX, Michel. Semântica e discurso: uma crítica à afirmação do óbvio. Campinas: Unicamp, 1995. 
